\title{
DETERMINANTES DO ACESSO À INFRA-ESTRUTURA URBANA NO MUNICÍPIO DE SÃO PAULO
}

\section{Renata Mirandola Bichir}

\section{Introdução}

Este artigo contrapõe-se ao foco da literatura brasileira de estudos urbanos desenvolvida principalmente nas décadas de 1960 e 1970, a qual se preocupou especialmente com a análise dos diversos mecanismos que contribuíam para a configuração de espaços segregados, no contexto de discussões mais amplas a respeito do modelo de desenvolvimento capitalista brasileiro (Santos, 1979; Smolka, 1992; Bonduki e Rolnik, 1982). Ao invés de discutir os processos de formação dos espaços periféricos e as causas da segregação residencial, pretende-se analisar possíveis conseqüências da segregação do ponto de vista do acesso dos mais pobres a serviços urbanos.

Segregação residencial é um tema que está longe ser consensual, tanto em termos conceituais

Artigo recebido em julbo/2007

Aprovado em novembro/2008 quanto dos grupos sociais que devem ser privilegiados na análise, assim como dos mecanismos que estão na causa do fenômeno ou suas principais conseqüências. Diversos autores a associam à falta de acesso a serviços essenciais e a políticas públicas (Camargo et al., 1976; Kowarick, 1979). Outros associam a segregação ao processo de formação das áreas periféricas nas principais metrópoles brasileiras (Santos e Bronstein, 1978; Santos, 1979; Vetter e Massena, 1981; Bonduki e Rolnik, 1982; Villaça, 2000). Muitos destacam a relevância da concentração espacial de certos grupos sociais na definição do fenômeno da segregação (Villaça, 2000; Marques e Torres, 2005), divergindo, entretanto, quanto aos grupos sociais que devem ser analisados e, sobretudo, quanto aos mecanismos que geram essas distribuições espaciais.

A literatura internacional também apresenta diversas formas de abordagem da questão. A segregação 
residencial tem longa tradição de discussão em outros países, especialmente nos Estados Unidos (Wilson, 1987; Massey e Denton, 1993; Jargowski, 1997), assim como na França (Wacquant, 2001; Préteceille, 2003). Nos Estados Unidos, o debate em torno da pobreza e da segregação urbana é polarizado ideologicamente entre conservadores inscritos no registro do blaming the victim (Murray, 1984) e liberais preocupados com processos estruturais mais amplos (Wilson, 1987). Além disso, os estudos sobre segregação estão centrados na questão racial (Kowarick, 2001 e 2003; Recio, 2003; Massey e Denton, 1993). O enquadramento da questão social na França é completamente distinto, com destaque para o papel do Estado na (re)inserção social dos indivíduos (Kowarick, 2001 e 2003; Recio, 2003). A tradição francesa elaborou importantes estudos sobre segregação, como as análises de Wacquant $(1996,2001)$ a respeito dos guetos norte-americanos e as análises de Préteceille (2003) a respeito da segregação sociorresidencial nas cidades francesas. Na América Latina, estudos recentes sobre a dinâmica da segregação em várias cidades revelam a complexidade do tema e dos próprios padrões de configuração espacial dos grupos sociais (Sabatini et al., 2005; Kaztman e Retamoso, 2005; Groisman e Suárez, 2005; Torres e Bichir, 2008).

Neste artigo, a segregação é entendida como separação dos grupos sociais no espaço, gerando relativa homogeneidade social interna e heterogeneidade em relação aos grupos sociais do entorno, conceito este que permite a análise empírica do fenômeno. Nesse sentido, pretende-se analisar as possíveis conseqüências da segregação (e não as suas causas), entre elas seu impacto sobre as condições de acesso às políticas de infra-estrutura urbana. Essa política foi escolhida devido ao seu papel fundamental na conformação do espaço urbano e na distribuição heterogênea de benefícios públicos entre os diversos segmentos da população e entre as diferentes áreas da cidade de São Paulo (Bichir, 2005).

Os dados apresentados baseiam-se em um survey representativo de $40 \%$ da população mais pobre residente no município de São Paulo - população que, à época, contava com um rendimento familiar mensal de até $\mathrm{R} \$ 1.100,00$-, realizado em novembro de 2004 pelo Centro de Estudos da
Metrópole (CEM-Cebrap). O objetivo daquele estudo foi analisar as condições de acesso a diversas políticas públicas de modo a verificar os níveis de cobertura auferidos e identificar os principais determinantes do acesso a essas políticas. O foco na população mais pobre permitiu verificar, para além da renda, quais são as demais dimensões intervenientes (Figueiredo et al., 2005). As informações coletadas foram endereçadas, permitindo a criação de indicadores espaciais e o cruzamento das informações obtidas com dados de outras fontes, como por exemplo os censitários. Uma vez que a amostra do survey foi desenhada de forma a captar situações de pobreza nas diferentes macrorregiões da cidade (pobres residentes em áreas centrais, em áreas intermediárias e em áreas periféricas, conforme apresentado no Mapa 1 anexo), foi possível testar o impacto da segregação residencial sobre as condições de acesso a serviços.

Além da relevância da segregação residencial, foram considerados outros condicionantes do acesso aos serviços de infra-estrutura, tais como variáveis individuais, condição de migração, participação associativa, entre outros aspectos. Essas diferentes dimensões estão associadas a diversas matrizes explicativas e relacionam-se com a premissa de que os condicionantes do acesso a serviços urbanos são múltiplos, mesmo entre a população mais pobre do município.

$\mathrm{O}$ artigo apresenta, na segunda seção, os níveis de cobertura de serviços auferidos pela população de baixa renda de São Paulo e o indicador de acesso elaborado para a análise. Na terceira seção é apresentada breve discussão das principais explicações para o acesso a políticas públicas, apontando para os indicadores que foram construídos. A quarta seção apresenta a metodologia utilizada para avaliar a relevância de diversos indicadores na determinação das condições de acesso à infra-estrutura urbana e também os resultados obtidos nessa análise multivariada. Por fim, a quinta seção resume os resultados obtidos.

\section{Aspectos da infra-estrutura urbana no município de São Paulo}

No survey realizado em 2004, foram avaliadas as condições de acesso à infra-estrutura urbana, 
incluindo as redes de água, esgoto, iluminação pública, energia elétrica e coleta de lixo, além da presença de calçamento, transporte público próximo, e parques e praças. Em primeiro lugar, destacam-se os elevados níveis de cobertura em quase todos os serviços, especialmente nos casos da água, energia elétrica e coleta de lixo, praticamente universalizados mesmo entre a população mais pobre. Porém, tratando-se em rede de esgoto, calçamento, iluminação pública, transporte próximo e presença de parques e áreas verdes, as coberturas são inferiores (Tabela 1).

Considerando essa elevada cobertura geral, optou-se pela construção de um indicador mais exigente de acesso, que reuniu esses serviços. A agregação foi possível porque esses serviços mostraram-se fortemente correlacionados, o que indica que a provisão dos mesmos não se dá de modo isolado, mas é parte de uma dinâmica mais geral dos serviços urbanos. Estes contribuem para a chamada produção do "ambiente construído" - a maioria fica incrustada no espaço, adquire materialidade - e devem chegar à porta dos domicílios (ou mesmo em seu interior), ao contrário do que ocorre no caso dos equipamentos de educação e saúde, por exemplo.

Para cada variável que compõe o indicador de acesso a serviços urbanos foram consideradas duas situações: adequada (provisão dos serviços) ou não
Tabela 1

Cobertura de Alguns Serviços Urbanos nos Domicílios mais Pobres (\%). Município de São Paulo, 2004.

\begin{tabular}{lc}
\hline Serviço & Cobertura \\
\hline Energia elétrica & 97,40 \\
Rede de Água & 96,70 \\
Coleta de lixo & 92,70 \\
Água chega todo dia & 92,00 \\
Transporte público próximo & 89,60 \\
Calçamento & 83,70 \\
Iluminação pública & 76,00 \\
Esgoto & 75,00 \\
Parque ou praça próximos & 46,80 \\
\hline
\end{tabular}

Fonte: CEM-Cebrap/Ibope. Survey de acesso da população mais pobre de São Paulo a serviços públicos, nov. 2004.

adequada (não provisão dos serviços), sendo a provisão adequada identificada pelo valor um (1) e a provisão não adequada pelo valor zero (0). $\mathrm{O}$ indicador final corresponde a uma média dessas variáveis, variando em uma escala de zero a um, onde zero representa a pior situação e um a melhor (Tabela 2).

Tabela 2

Componentes do Indicador de Acesso a Serviços Urbanos. Município de São Paulo, 2004.

\section{Componentes}

Situação

\begin{tabular}{lcc} 
& Adequada & Não adequada \\
\cline { 2 - 3 } 1. Domicílio ligado à rede pública de água com canalização interna & $1=\operatorname{Sim}$ & $0=$ Não \\
2. Freqüência com que a água chega ao domicílio & $1=$ Todo dia & $0=$ Outras situações \\
3. Domicílio ligado à rede pública de esgoto & $1=\operatorname{Sim}$ & $0=$ Não \\
4. Domić́lio ligado à rede pública de energia elétrica & $1=\operatorname{Sim}$ & $0=$ Não \\
5. Coleta de lixo no domicílio & $1=\operatorname{Sim}$ & $0=$ Não \\
6. Existência de calçamento na rua do domicílio & $1=\operatorname{Sim}$ & $0=$ Não \\
7. Existência de iluminação pública na rua do domicílio & $1=\operatorname{Sim}$ & $0=$ Não \\
8. Existência de transporte público próximo ao domicílio & $1=\operatorname{Sim}$ & $0=$ Não \\
9. Existência de parque ou praça próxima ao domicilio & $1=\operatorname{Sim}$ & $0=$ Não
\end{tabular}

Fonte: CEM-Cebrap/Ibope. Survey de acesso da população mais pobre de São Paulo a serviços públicos, nov. 2004. 
A maioria dos domicílios está classificada nas situações mais adequadas, dadas as altas coberturas observadas. Ou seja, de maneira geral é possível dizer que mesmo os domicílios mais pobres contam com níveis adequados de acesso a serviços urbanos. Os domicílios pior classificados nesse indicador provavelmente não contam com parques e praças próximas, podem enfrentar situações de intermitência no abastecimento de água e têm problemas com a rede de esgoto e com a iluminação pública, porém contam com rede de água, energia elétrica e coleta de lixo.

Além disso, esse indicador foi agregado em três grupos: serviços inadequados (0 a 0,88$)$; serviços deficientes $(0,88$ a 0,89$)$ e serviços adequados (de 0,89 a 1). Analisando a distribuição desse indicador segundo as grandes regiões do município (Tabela 3), é possível observar que há diferenciais significativos de acordo com o tipo de área: enquanto na área periférica 45,9\% dos domicílios contam com serviços inadequados, nas áreas centrais somente 22,1\% apresentam essa situação. Padrões similares são observados de acordo com outras variáveis territoriais, pois domicílios localizados em áreas de favela ou loteamentos irregulares também apresentam níveis de acesso inferiores. Esses resultados indicam que o acesso a esses serviços ainda apresenta problemas nas áreas mais segregadas.

Contudo, esses resultados não são suficientes para comprovar a hipótese de que existe relação entre segregação residencial e pior acesso a serviços urbanos. Em algumas interpretações, o pior acesso a serviços urbanos tem sido analisado não como fruto da segregação, mas como conseqüência das condições de ilegalidade do acesso à terra, que constituiriam barreiras à expansão dos investimentos públicos (World Bank, 1999; Maricato, 1996). Assim, de modo a avaliar mais detidamente os fatores que condicionam os níveis de acesso à infra-estrutura urbana, é necessário desenvolver análises mais complexas, como apresentado neste artigo.

\section{Condicionantes do acesso a políticas públicas}

Há diversas hipóteses explicativas para as condições de acesso a políticas públicas, especialmente quando se trata dos grupos mais pobres da população. Algumas abordagens destacam aspectos individuais dessas populações, suas características socioeconômicas e demográficas, tais como sexo, idade, renda, entre outras (Barros et al., 2001; Menezes-Filho e Pazello, 2005). Muitas análises destacam a relevância da atuação estatal na promoção dos serviços e políticas, apontando para as diferentes motivações que os agentes estatais - especialmente as burocracias - têm ou não para expandir os serviços para os grupos mais carentes, visando à sua reprodução (Marques, 2000). Na literatura dos anos 1980, destacou-se o papel dos movimentos sociais na explicação da expansão da provisão de serviços para áreas periféricas das metrópoles brasileiras (Jacobi, 1989; Sader, 1988; Gohn, 1991). Outros autores, mais recentemente, apontam a relevância de redes de relações sociais de diversos

Tabela 3

Indicador Sintético de Acesso a Serviços Urbanos e Ambiente Construído, Segundo Macrorregiões (\%). Município de São Paulo, 2004.

\begin{tabular}{|c|c|c|c|c|}
\hline & \multicolumn{3}{|c|}{ Macrorregião } & \\
\hline & Periférica & Intermediária & Central & \\
\hline Serviços Inadequados & 45,90 & 27,10 & 22,10 & 38,90 \\
\hline Serviços Deficientes & 33,70 & 33,90 & 27,60 & 33,30 \\
\hline Serviços Adequados & 20,40 & 39,10 & 50,30 & 27,80 \\
\hline Total & 100,00 & 100,00 & 100,00 & 100,00 \\
\hline
\end{tabular}

Fonte: CEM-Cebrap/Ibope. Survey de acesso da população mais pobre de São Paulo a serviços públicos, nov. 2004. 
tipos, advindas de grupos de parentesco, associações comunitárias, instituições religiosas e laicas (Gurza Lavalle e Castello, 2004; Almeida e D’Andrea, 2004). Nessa seção, apresentamos algumas dessas dimensões intervenientes no acesso a políticas públicas, particularmente aquelas que puderam ser testadas na análise a partir dos dados do survey supracitado, bem como os indicadores que foram construídos para cada uma dessas dimensões explicativas.

\section{Estado}

Estudar políticas públicas - que, assim como políticas de infra-estrutura urbana, configuram-se em cristalizações das ações estatais na cidade - é relevante no entendimento dos diferentes padrões de conformação do território, pois, como afirma Préteceille (2003, p.10), referindo-se à metrópole parisiense, "[...] a qualidade dos espaços residenciais não é o resultado da distância em relação ao centro ou da evolução histórica da cidade, mas é também o efeito das políticas públicas, que podem transformar esta qualidade através da criação de infra-estruturas de equipamentos e serviços".

A própria atuação do Estado no espaço urbano, por meio das políticas públicas, pode contribuir para criar, reforçar ou reduzir mecanismos de segregação. O Estado tem forte influência na produção desses espaços segregados, pois sua atuação no ambiente construído, por meio de investimentos em infraestrutura e em outros equipamentos públicos, gera valorizações de certas áreas e desvalorização de outras. Isso faz com que a população mais pobre muitas vezes não possa arcar com os custos das benfeitorias - devido a mecanismos de renda da terra - e seja deslocada para outras áreas, distantes e desprovidas de infra-estrutura básica e equipamentos públicos, aumentando, desse modo, seus gastos com transporte e sua exposição a variados tipos de risco.

De modo a testar, ainda que indiretamente, a influência da atuação estatal, foi avaliado o impacto do investimento estatal em pequenas obras de infra-estrutura viária sobre as condições de acesso à infraestrutura urbana. Esse é o único indicador que não deriva dos dados do survey, mas sim de uma pesquisa consolidada em Marques (2003). ${ }^{1}$ Foram consideradas apenas obras de pequeno porte com recortes espaciais específicos - como obras de pavimentação de ruas e pequenos serviços de drenagem - que foram realizados no período 1975-2000 pela prefeitura (Bichir, 2005). Todos esses investimentos foram endereçados e então foi criado um indicador referente ao valor médio dos investimentos viários por área. A hipótese por trás desse indicador refere-se à possibilidade de locais com maiores investimentos estatais em infra-estrutura viária serem também locais mais servidos por infra-estrutura urbana, pois geralmente essas obras são realizadas de forma conjunta.

\section{Variáveis territoriais}

Como apontado, um conjunto importante de condicionantes do acesso a políticas refere-se às variáveis territoriais (Torres, 2005). Na construção desses indicadores, levou-se em consideração a escala da segregação, ou seja, o fato de que uma mesma cidade pode ser diferentemente segregada de acordo com a escala considerada (Sabatini, 2000). Essa distinção de escalas permite abordar a micro e a macrossegregação, sendo a microssegregação considerada numa escala geográfica mais detalhada (como, por exemplo, o isolamento espacial de determinados grupos sociais no interior de um bairro) e a macrossegregação numa escala espacial mais abrangente, como os padrões de aglomeração espacial de grupos sociais na cidade como um todo.

Em primeiro lugar, considerou-se a macrossegregação. Nessa escala bastante agregada, procurou-se avaliar a distância média de cada domicílio pobre em relação às áreas mais ricas (região Sudoeste do município) e também a relevância dos grandes tipos de área definidos no próprio desenho do survey (macrorregiões central, intermediária e periférica - ver Mapa 1, em anexo). A idéia por trás desses indicadores é testar o impacto da distribuição dos domicílios mais pobres na cidade como um todo, abordando as áreas mais ricas como pólos de atração de população, especialmente devido à maior oferta de empregos e serviços (Villaça, 2000).

Em uma escala intermediária, aqui denominada mesossegregação, procurou-se avaliar o impacto da renda do "ambiente" em que se insere o domicílio pobre analisado no survey. Nesse caso, seguiu-se a hipótese presente nos estudos de "efeitos de vizinhança" 
(neighborbood effects) de que domicílios pobres localizados em áreas ricas ou em ambientes também pobres enfrentam situações sociais bastante diversas, em que a situação de concentração espacial de pobreza é problemática em termos de mecanismos de reprodução da pobreza (Brooks-Gunn e Duncan, 1997; Yinger, 2001; Durlauf, 2001). Os indicadores construídos nesse caso foram as áreas segregadas segundo um indicador de concentração espacial de grupos sociais (Índice de Moran Lo$\mathrm{cal}^{2}$ ) e a renda média do chefe do domicílio em um raio de até $3 \mathrm{~km},{ }^{3}$ de modo a verificar o impacto das condições econômicas do ambiente em que se insere o domicílio de baixa renda.

Por fim, na escala mais desagregada espacialmente, a microssegregação, procurou-se testar os efeitos do ambiente local que poderiam ter impactos sobre as condições de vida de populações de baixa renda, como a residência em áreas de favela (Torres e Bichir, 2008). Nesse caso, os indicadores criados foram a renda média do chefe em um raio de até $500 \mathrm{~m}$ ao redor dos domicílios pobres e os domicílios pobres localizados em área de favela e loteamentos irregulares. ${ }^{4}$

\section{Fatores individuais}

Além da dimensão espacial, outras vertentes, presentes especialmente no âmbito da economia e da demografia, ressaltam a importância de fatores individuais no entendimento das condições de acesso a políticas públicas. Essas características sociais e demográficas da população alvo poderiam estimular maior acesso a informações e maior conhecimento sobre os mecanismos de funcionamento e os canais de acesso a certas políticas públicas (Barros et al., 2001). Neste artigo foram testadas diversas características dos responsáveis pelos domicílios mais pobres - sexo, idade, cor, tempo médio de estudo -, bem como a renda familiar mensal, informações disponíveis no survey.

\section{Participação associativa}

Muitos autores mobilizam em suas explicações o papel dos movimentos sociais urbanos que teriam contribuído para redirecionar os investimentos estatais para as áreas periféricas após sua emergência nos anos de 1970 e início dos 1980 Jacobi, 1989; Sader, 1988; Gohn, 1991). Outros apontam a importância dos grupos de parentesco e dos vínculos com instituições religiosas ou laicas (Gurza Lavalle e Castello, 2004; Almeida e D'andrea, 2004) como aspectos que teriam influência sobre o acesso a serviços públicos, especialmente no âmbito de comunidades carentes. Assim, foram testadas, por meio das informações disponíveis no survey, a influência dos vínculos dos indivíduos mais pobres da população com associações religiosas e com associações civis de diversos tipos, bem como sua preferência partidária, de modo a avaliar o impacto do associativismo, das relações comunitárias e do acesso a canais de informação sobre os serviços considerados.

\section{Tempo no bairro}

Também há vertentes que destacam a importância do tempo de residência em um determinado local do ponto de vista do incremento das condições de acesso a certos serviços. Apesar de criticar-se a tese do "evolucionismo urbano" - segundo a qual o Estado tenderia a expandir os serviços primeiro para as áreas mais centrais e consolidadas, que seriam mais "visíveis" para as políticas públicas, levando mais tempo para atingir as áreas mais distantes -, considerase que o maior tempo de residência em certas áreas pode contribuir para a realização de uma série de melhorias nas residências, nos bairros, e conseqüentemente, na qualidade de vida dessas populações (Kowarick, 2005). Alguns estudos demonstram ainda que nas áreas periféricas o tempo de residência no bairro é importante para o adensamento das redes de relações e para a capacidade de organização, inclusive para a possibilidade de demandar serviços junto ao poder público (Almeida e D’Andrea, 2005).

Todos esses indicadores foram considerados na análise das condições de acesso dos mais pobres à infra-estrutura urbana em São Paulo, como apresentado a seguir.

\section{Modelo de acesso à infra-estrutura urbana}

De modo a explorar os diversos condicionantes do acesso à infra-estrutura urbana, foi necessária a utilização de uma análise multivariada que per- 
mitisse testar conjuntamente os diferentes indicadores discutidos. Nesse sentido, esta seção apresenta o modelo de análise utilizado para testar as relações entre os diversos conjuntos de indicadores e os níveis de acesso aos serviços urbanos (o indicador sintético de acesso apresentado na segunda seção).

Foi utilizado o modelo estatístico de CHAID (Chi-squared Automatic Interaction Detector), técnica utilizada para estudar a relação entre uma variável dependente e uma série de variáveis explicativas (preditoras) que interagem entre si, estabelecendo uma hierarquia das influências das variáveis consideradas. O modelo testa todas as partições possíveis de suas categorias - em tabelas de dupla entrada com as relações entre a variável dependente e cada preditora -, escolhendo aquela que apresenta o maior valor para a estatística qui-quadrado. Os dados são agrupados segundo a partição escolhida e uma nova análise é realizada dentro de cada subgrupo, repetindo-se o procedimento anterior para a variável dependente e as demais preditoras. Esse processo é repetido sucessivamente até que os grupos divididos cheguem a um número mínimo de casos estipulado. É possível considerar as variáveis indicadas no resultado final como os condicionantes mais importantes na explicação da variabilidade da variável dependente. Esse modelo é bastante útil em análises exploratórias, quando as associações entre as variáveis de interesse não são bem conhecidas (Figueiredo et al., 2005). Além de testar, ao mesmo tempo, o impacto de diversas variáveis explicativas, outra vantagem deste método é permitir a caracterização dos perfis daqueles que têm ou não acesso a certa política.

Neste estudo, o modelo multivariado partiu do indicador sintético de acesso à infra-estrutura como variável dependente. Assim, o modelo procurou identificar os principais condicionantes para os três níveis de acesso do indicador: acesso inadequado, acesso deficiente e acesso adequado. Como variáveis explicativas, foram utilizadas aquelas discutidas na seção anterior, apresentadas na Tabela 4, com a indicação daquelas que permaneceram e as que foram excluídas da análise.

Tabela 4

Variáveis Testadas no Modelo de Chaid. Município de São Paulo, 2004. ${ }^{5}$

\section{Variáveis individuais}

Permaneceu no modelo

Sexo do responsável pelo domicílio (masculino ou feminino)

Idade do responsável pelo domicílio (entre 18 e 29 anos; entre 30 e 49 anos; acima de 50 anos)

Cor do responsável pelo domicílio (branco ou não-branco)

Anos de estudo do responsável pelo domicílio (0 a 3; 4 a 7; 8 a 10 e 11 anos e mais)

Renda familiar per capita (s.m.)

\section{Não}

Sim

Não

Não

Sim

\section{Variáveis territoriais}

Macrorregiões do survey (central, intermediária e periférica)

Áreas segregadas segundo Índice de Moran Local

Distância às centralidades da RMSP ( 0 a $1 \mathrm{~km}$; mais de 1 a $5 \mathrm{~km}$; mais de 5 a $10 \mathrm{~km}$; mais de $10 \mathrm{~km})$

Renda do chefe no microambiente (s.m. - valores de 2000)

Renda do chefe no mesoambiente (s.m. - valores de 2000)

Domicílios em área de favelas ou loteamentos irregulares (sim ou não)

\section{Migração}

Tempo no bairro (anos)

Nasceram fora do Estado de SP (sim ou não)

Migrante da região Nordeste (sim ou não)

\section{Associativismo}

Participação quinzenal em associação religiosa (sim ou não)

Participação anual em algum tipo de associação não religiosa (sim ou não)

Preferência por algum partido político (sim ou não)

Sim

Não

Sim

Sim

Não

Sim

Estado

Níveis de investimento viário por área (baixo, intermediário e alto)

Sim

Não

Não

Não

Não

Não

Fonte: CEM-Cebrap/Ibope. Survey de acesso da população mais pobre de São Paulo a Serviços Públicos, nov. 2004. 
O modelo final obtido por meio da técnica de Chaid é apresentado na Figura 1, a seguir, e permi- te verificar as variáveis que se mostraram mais associadas com o indicador de infra-estrutura urbana.

Figura 1

Modelo de Chaid para o Indicador de Acesso à Infra-estrutura Urbana.

Município de São Paulo, 2004.

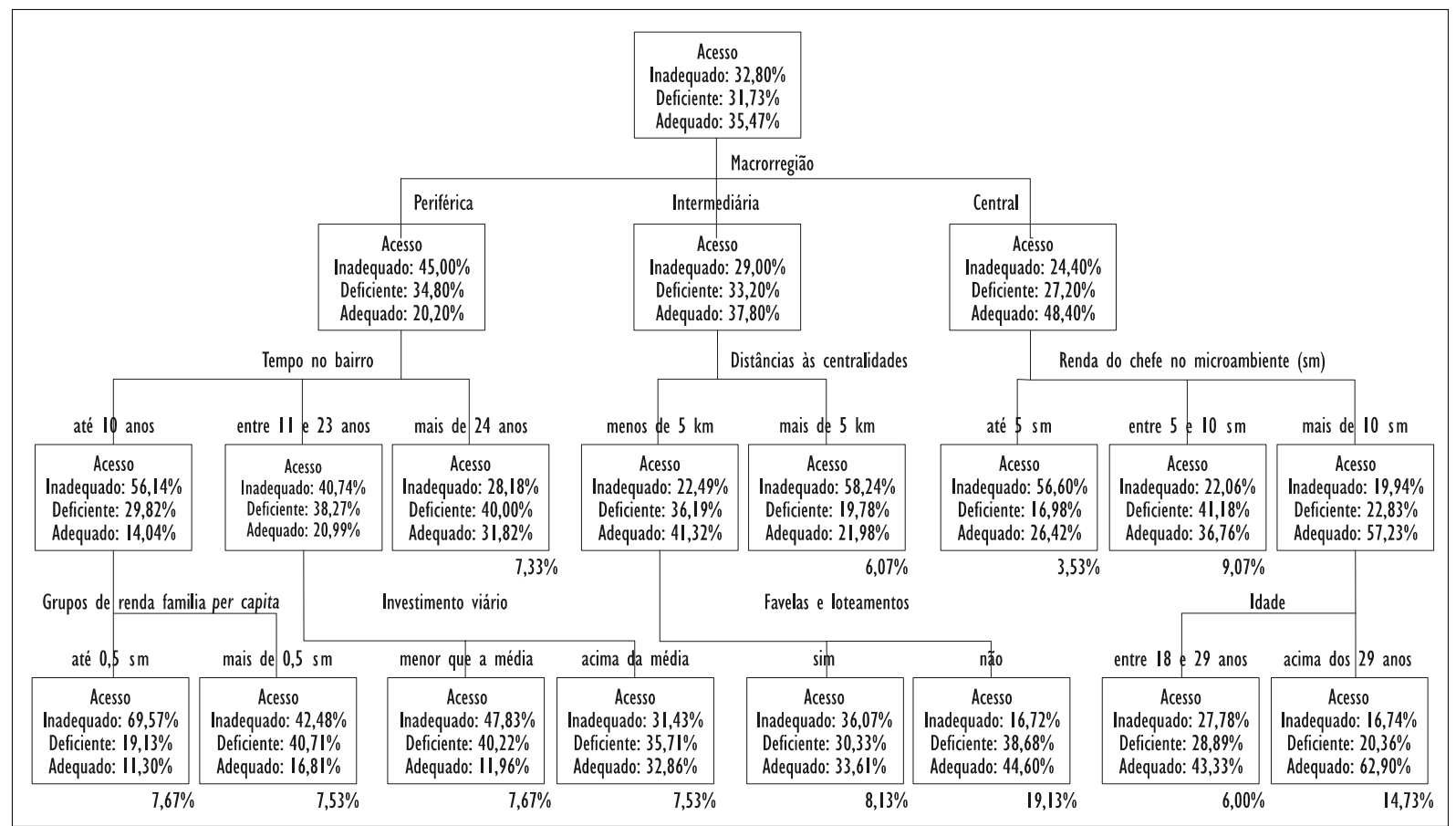

Nota: Nível de significância de 5\%.

Nessa figura, a variável dependente corresponde ao indicador de acesso à infra-estrutura urbana dividido em três níveis de acesso. O primeiro ramo da árvore apresenta as variáveis mais importantes para explicar o acesso a esses serviços - ou seja, a variável explicativa mais associada com o indicador de infra-estrutura urbana. A importância das variáveis cai sucessivamente nos ramos inferiores, o que significa que as associações observadas são menores. No interior de cada célula - que representa um recorte dentro do universo de domićlios pobres do município de São Paulo, configurando um grupo com características particulares - estão indicados os percentuais de acesso inadequado, de acesso deficiente e de acesso adequado aos serviços urbanos. Os percentuais apresentados sob cada quadro indicam a participação daquele grupo no total de domicílios pobres do município.
Em primeiro lugar, o modelo indica que o principal elemento na diferenciação das condições de acesso à infra-estrutura urbana é a macrorregião de residência, ou seja, o fato de o domicílio pobre estar localizado na área central, intermediária ou periférica, destacando a relevância da escala da macrosegregação para o entendimento das condições de acesso a serviços urbanos em São Paulo. Observa-se que os níveis de acesso adequado caem à medida que se passa da área central para a área periférica, e que há maior proporção de domicílios pobres localizados em áreas periféricas com níveis de acesso inadequados: 45,0\%, contra 29,0\% dos domicílios localizados em áreas intermediárias e 24,4\% em áreas centrais. Esse resultado confirma a hipótese da relevância da segregação residencial para o acesso a políticas públicas, indicando que mesmo em contextos de elevada cobertura há diferenciais 
de acesso de acordo com a região de moradia. A seguir, são especificadas as condições de acesso dentro de cada uma dessas macrorregiões.

\section{Áreas periféricas}

Entre os domicílios localizados em áreas periféricas, a segunda dimensão mais importante é o tempo de permanência no bairro, o que aponta para a relevância do grau de consolidação dos domicílios como aspecto que pode garantir melhores condições gerais de infra-estrutura urbana. Os dados indicam que, quanto maior esse tempo, maior a proporção de domicílios com acesso adequado a serviços urbanos.

Entre os domicílios chefiados por pessoas há menos de dez anos no bairro, constata-se outra diferenciação, referente à renda familiar per capita. Os domicílios em que a renda familiar per capita é de no máximo meio salário mínimo contam com níveis de acesso muito piores do que domicílios cujos chefes também estão há pouco tempo no bairro, mas que têm renda familiar per capita superior a meio salário mínimo. Esse grupo, formado por domicílios localizados em áreas periféricas, com chefes há pouco tempo no bairro e com menor renda familiar per capita representa a pior situação observada entre todos os grupos analisados: quase $70 \%$ dos domicílios nessa situação têm níveis inadequados de acesso a serviços urbanos, sendo provavelmente áreas bastante precárias, nas franjas do município, desprovidas de esgotamento sanitário, calçamento e outros serviços. Esses resultados parecem confirmar certa relevância da dimensão econômica mesmo entre os domicílios mais pobres do município, indicando o funcionamento de mecanismos de renda da terra que deslocam as populações com menos recursos para as áreas mais precárias (Vetter e Massena, 1981).

Analisando os domicílios que são chefiados por pessoas que estão entre 11 e 23 anos no bairro, verifica-se que há diferenciação no acesso de acordo com os níveis de investimentos viários que foram realizados na região ao longo do período 1975 2000. Observa-se que os domicílios que estão em áreas que receberam volume de investimento viário acima da média contam com melhores níveis de acesso a serviços urbanos. Esse resultado provavelmente sofre o efeito do corte temporal dos investimentos viários analisados: aqueles que estão há menos tempo no bairro não se beneficiaram dos investimentos viários localizados nesse período; aqueles que estão há mais tempo no bairro provavelmente beneficiaram-se de investimentos estatais realizados anteriormente.

Por fim, entre os domicílios cujos chefes estão há mais de 24 anos no bairro, verifica-se que não há mais nenhum indicador diferenciando os níveis de acesso a serviços urbanos (não há um terceiro ramo da árvore). Esse resultado indica que, nesses casos, apenas o grau de consolidação das áreas já é suficiente para explicar os melhores níveis de acesso dentre aqueles que estão em áreas periféricas - níveis estes que, contudo, são inferiores àqueles observados em áreas intermediárias e centrais, conforme apresentado a seguir. Em termos comparativos, domicílios localizados nesse grupo têm menos acesso inadequado a serviços urbanos do que domicílios localizados em áreas de favela na macrorregião intermediária, o que indica que, para além dos efeitos da macrossegregação é necessário atentar para situações de microssegregação que podem ter impacto sobre as condições de acesso.

\section{Área intermediária}

No caso desses domicílios, a segunda dimensão mais relevante é a distância em relação às centralidades da RMSP, com domicílios mais próximos das áreas centrais (a no máximo $5 \mathrm{~km}$ ) contando com melhores níveis de acesso do que domicílios mais distantes (a mais de $5 \mathrm{~km}$ dessas centralidades). Esse resultado parece confirmar a relevância da proximidade às áreas centrais para a obtenção de melhores níveis de acesso a serviços: enquanto $41,32 \%$ dos domicílios localizados a até $5 \mathrm{~km}$ das centralidades da RMSP contam com serviços urbanos adequados, somente 21,98\% dos domicílios a mais de $5 \mathrm{~km}$ das centralidades contam com tal nível de acesso.

Entre os domicílios que estão mais próximos das áreas centrais, o terceiro elemento de diferenciação é a moradia em áreas de favela ou loteamentos irregulares: enquanto 44,6\% dos domicílios não 
localizados em áreas de favela ou loteamentos possuem níveis de acesso adequados, apenas 33,61\% dos domicílios localizados nessas áreas apresentam esse mesmo nível. Além da relevância da microssegregação, esses resultados apontam para a existência de certas barreiras institucionais ao investimento e para a "invisibilidade" dessas áreas aos olhos do poder público (Torres e Bichir, 2008).

Área central

No caso dos domicílios localizados em áreas centrais, a segunda dimensão mais relevante é a renda do microambiente, sendo que quanto maior for essa renda, mais adequados serão os níveis de acesso. Esses resultados reforçam a importância da dimensão territorial nessa escala menos agregada, destacando o impacto das características da vizinhança dos domicílios para o entendimento dos padrões de acesso a serviços.

Entre os domicílios localizados na região central, mas em áreas com microambiente mais pobre (renda do chefe de no máximo $5 \mathrm{sm}$ ), há maior proporção de acesso inadequado a serviços urbanos do que no caso dos domićlíios localizados em áreas periféricas (56,6\% contra 45\%). Esse resultado parece indicar situações localizadas de precariedade no interior da área central, provavelmente áreas de cortiços ou de favelas, com acesso deficiente aos serviços urbanos. Como demonstram Marques e Saraiva (2005), as condições sociais de algumas favelas localizadas na região central do município são mais precárias do que aquelas observadas nas favelas localizadas em áreas periféricas.

Entre os domicílios localizados em microambiente com renda intermediária, os níveis de acesso a serviços urbanos são melhores do que os domicílios pobres localizados em ambientes também pobres e piores do que os domicílios localizados em ambientes ricos.

Nas áreas de mais alta renda do microambiente (acima de $10 \mathrm{sm}$ ), verifica-se a relevância da idade do chefe de domicílio: aqueles cujos chefes são mais jovens (entre 18 e 29 anos) possuem menores níveis de acesso adequado a serviços urbanos. Esse resultado parece apontar para as dificuldades enfrentadas no início de ciclo de vida familiar por parte de chefes de família jovens e de baixa renda, gerando inserção mais precária na cidade. Em termos comparativos, esse grupo chefiado por pessoas mais jovens tem níveis de acesso um pouco inferiores àqueles observados no caso dos domicílios localizados na macrorregião intermediária, em áreas próximas às centralidades e que não são áreas de favelas ou loteamentos.

Por outro lado, os domicílios localizados em área central, em microambiente mais rico e chefiados por pessoas com mais de 29 anos apresentam os níveis de acesso a serviços urbanos mais adequados entre todos aqueles considerados no modelo $62,9 \%$ dos domicílios desse grupo possuem níveis de acesso adequados.

De maneira geral, apesar desses diferenciais, é possível dizer que os níveis médios de acesso observados no caso dos grupos de domicílios localizados na região central são mais elevados do que os grupos de domicílios localizados em outras regiões.

\section{Considerações finais}

Recentemente, autores começaram a alertar para heterogeneidade das áreas periféricas, indicando que cada vez mais é preciso falar em periferias, com características bastante peculiares, e não mais em periferia, pois esse rótulo abrangente coloca sob o signo da homogeneidade realidades muito distintas. Entretanto, poucos realmente conseguem demonstrar como se desdobra essa heterogeneidade, não só do ponto de vista das condições gerais de vida como da perspectiva do acesso a políticas públicas. Esse artigo pretendeu contribuir para o preenchimento dessa lacuna, utilizando dados de survey, ferramentas de geoprocessamento e um modelo multivariado de acesso para mostrar como são complexas as condições de acesso a serviços públicos mesmo entre as populações mais pobres de São Paulo. Logrouse demonstrar também a relevância da segregação residencial, em suas múltiplas manifestações, sobre as condições de acesso à infra-estrutura urbana.

Os resultados indicaram que as condições de acesso à infra-estrutura urbana entre os mais pobres são explicadas por um conjunto bastante diversificado de fatores, apontando a complexidade 
das situações de acesso. Além disso, mostrou-se que, apesar das coberturas relativamente altas dos serviços urbanos, há barreiras localizadas ao acesso que precisam ser enfrentadas pelo poder público, sendo que este deve estar atento para a heterogeneidade das situações de segregação residencial, que se manifestam em diferentes escalas.

O grupo com acesso mais inadequado entre todos é formado por domicílios localizados em áreas periféricas, cujos chefes estão há pouco tempo no bairro e a renda familiar per capita é baixa situação que representa 7,67\% do total de domićlios mais pobres do município. Entretanto, situações inadequadas também são observadas na área intermediária - no caso dos domićlíos distantes das centralidades - e mesmo na área central, no caso de microambientes pobres. Esses resultados reforçam a necessidade de um olhar atento para as diversas situações de privação existentes no município e para a relevância da escala da segregação - ou seja, a "lupa" dos formuladores de políticas deve ser bem acurada, indo além das grandes regiões da cidade e atentando para situações particulares.

Por outro lado, com os níveis de acesso mais adequados a serviços urbanos, estão os domićlios localizados em áreas intermediárias, próximos às centralidades e fora de áreas de favela (situação em que se incluem $19,13 \%$ do total de domicílios mais pobres do município) e o grupo de domicílios localizados na macrorregião central, em microambiente rico e chefiado por pessoas mais velhas. Verifica-se então que a maior parcela dos domicílios pobres enfrenta poucas situações inadequadas de acesso a serviços urbanos.

De maneira geral, as variáveis territoriais foram aquelas que mais geraram diferenciais nos níveis de acesso a serviços urbanos, especialmente as relacionadas com a escala da macrossegregação, ou seja, ao fato de os domicílios estarem localizados em áreas centrais, intermediárias ou periféricas. Seguindo Marques e Bichir (2001), é possível pensar em dois mecanismos principais para esse menor nível de cobertura nas áreas periféricas. O primeiro estaria relacionado às burocracias responsáveis por esses serviços: de modo a garantir a sua própria reprodução, os técnicos estatais dependem dos desdobramentos das políticas implementadas por seus órgãos, o que os estimularia a expandir as políticas de infra-estrutura urbana para novas fronteiras. Contudo, para além das motivações das burocracias, é importante considerar uma segunda dinâmica, denominada por Marques (2000) de "seletividade hierárquica das políticas". De acordo com essa abordagem, a cultura técnica da burocracia de certos setores da administração pública tem conseqüências para a implementação das políticas, fazendo com que estas sejam expandidas prioritariamente - e com melhor qualidade - para as áreas mais ricas das cidades, sendo implantadas posteriormente nas áreas mais periféricas (Marques, 2000). Também é possível pensar nas relações entre as burocracias responsáveis pela provisão de serviços urbanos com as empresas privadas contratadas para a realização dos mesmos, o que certamente tem impacto sobre as áreas da cidade que são privilegiadas (Marques, 2003). Entretanto, essas dimensões não puderam ser exploradas com os dados aqui disponíveis, sendo necessárias análises qualitativas mais aprofundadas para a compreensão dos mecanismos envolvidos no caso da atuação das burocracias, seguindo a linha das pesquisas desenvolvidas por Marques (2000, 2003).

Também no plano da macrossegregação, verificou-se a relevância das distâncias às áreas socioeconomicamente bem inseridas da RMSP, reforçando a hipótese da importância das áreas centrais como pólos de concentração de empregos, serviços e oportunidades em geral, como apontado por diversos autores (Villaça, 2000; Sabatini, 2004).

Além da macrossegregação, verificou-se a relevância de dimensões de microssegregação. A renda do chefe no microambiente mostrou ser relevante na especificação dos níveis de acesso observados em áreas centrais, com domicílios pobres localizados em ambientes mais ricos contando com melhores níveis de acesso. Esses resultados apontam para a relevância da vizinhança, ou seja, a importância das características do entorno dos domicílios para os níveis de acesso a serviços urbanos auferidos (Massey e Denton,1993). E, no caso da renda, reforçam o argumento dos economistas, relativo ao funcionamento do mercado de terras e seu impacto sobre o acesso a serviços urbanos.

A localização em áreas de favela ou loteamentos irregulares, por sua vez, contribuiu para especificar 
as condições de acesso dos domicílios localizados em áreas intermediárias, porém próximos do centro, representando níveis menos adequados de acesso. Esse resultado indica a relevância da dimensão da posse da terra - a grande questão é como expandir serviços estatais para áreas ilegais. Verificou-se que as áreas de favela e de loteamentos irregulares ainda sofrem com a menor penetração de serviços urbanos, devido à "invisibilidade" dessas áreas para o poder público, às diversas barreiras institucionais aos investimentos estatais e a mecanismos de segregação.

Além das variáveis territoriais, o indicador relativo ao grau de consolidação da área em que se localiza o domicílio - tempo que o chefe de domicílio reside no bairro - também se mostrou relevante, indicando que aqueles que estão há mais tempo na área contam com níveis mais adequados de serviços urbanos. Essas áreas de ocupação mais antiga podem ser marcadas por maior grau de organização e por maior densidade das redes de relações (o que só pode ser verificado por meio de outras análises), gerando maior potencial de mobilização e poder de demanda junto ao poder público.

Observou-se ainda a relevância do Estado, por meio dos investimentos em infra-estrutura viária, ainda que em patamar menos significativo. Esses investimentos mostraram-se importantes especialmente nas áreas periféricas com grau de consolidação intermediário. Seria importante avançar no entendimento do impacto dos investimentos estatais, analisando os investimentos em infra-estrutura urbana propriamente dita.

Por sua vez, as variáveis individuais apresentaram relevância reduzida, pois serviram somente para apontar casos específicos de acesso no caso das áreas centrais - caso da variável "idade do responsável pelo domicílio" - e nas áreas periféricas - caso da "renda familiar per capita". As variáveis relativas à participação em associações civis e religiosas não se mostraram diretamente significativas no modelo. Entretanto, essa dimensão do associativismo parece ter certa relevância indiretamente, uma vez que o indicador de tempo de residência no bairro - que pode representar uma próxi da potencial de mobilização dessa população - mostrou-se relevante. Novamente, estudos de caso seriam necessários para aprofundar esse ponto.
Todos esses resultados reforçam a complexidade das condições de acesso a políticas entre os mais pobres e a permanência de uma série de desigualdades de acesso mesmo quando o Estado chega às áreas periféricas das grandes cidades. Além disso, destaca-se aqui que a segregação é um problema de política pública, especialmente quando se considera que ela constitui mecanismo particularmente relevante de reprodução das desigualdades socioeconômicas.

\section{Notas}

1 Essa pesquisa analisou os padrões de investimento em infra-estrutura viária - obras como canalização de córregos, abertura de grandes vias, drenagem, pavimentação, entre outras - no município de São Paulo no período 1975-2000. Para maiores detalhes, ver Marques, 2003.

2 Esse índice estima o grau de homogeneidade ou diferença entre áreas urbanas vizinhas entre si de acordo com uma dada variável de interesse e permite a identificação de clusters de pobreza, sendo uma medida propriamente espacial da segregação (Bichir, Torres e Ferreira, 2005).

3 Essa variável foi construída por meio de geoprocessamento, com base nos setores censitários de 2000. A partir de cada questionário do survey endereçado, verificou-se a informação relativa à renda do chefe de domicílio em um raio de três quilômetros, informação que se transformou em um atributo da base do survey.

4 Esse indicador também foi obtido por meio de georreferenciamento, associando-se os pontos do survey com a base de favelas e loteamentos irregulares desenvolvida pelo CEM (Marques, Torres e Saraiva, 2003).

5 Todas essas variáveis foram criadas a partir dos dados do survey supracitado. A única exceção refere-se à variável "níveis de investimento viário por área", criada a partir de dados de uma pesquisa anterior sobre investimentos viários em São Paulo (ver nota 3).

\section{BIBLIOGRAFIA}

ALMEIDA, R. \& D'ANDREA, T. (2005), “Estrutura de oportunidades em uma favela de São Paulo", in E. Marques e H. Torres (orgs.), São 
Paulo: segregação, pobreza e desigualdade sociais, São Paulo, Senac.

BARROS, Ricardo Paes et al. (2001), "Determinantes do desempenho educacional no Brasil”, in IPEA, Textos para discussão, 834. Rio de Janeiro, IPEA.

BICHIR, R. (2005), "Investimentos viários de pequeno porte no município de São Paulo: 19752000", in E. Marques e H. Torres (orgs.), São Paulo: segregação, pobreza e desigualdade sociais, São Paulo, Senac.

BONDUKI, N. G. e ROLNIK, R. (1982), "Periferia da Grande São Paulo: reprodução do espaço como expediente de reprodução da força de trabalho". In: E. Maricato, A produção capitalista da casa (e da cidade) no Brasil industrial. 2. ed. São Paulo, Alfa-Ômega.

BROOKS-GUNN, J. \& DUNCAN, G. (eds.). (1997), Neighborhood poverty - policy implications in studying neighborhoods. Nova York, Russell Sage Foundation, vol. 2.

CAMARGO, C. et al. (orgs.). (1976), São Paulo, 1975: crescimento e pobreza. São Paulo, Loyola.

DURLAUF, S. (2001), "The membership theory of poverty: the role of group affiliations in determining socioeconomic outcomes", in S. Danziger e R. Haveman (eds.). Understanding Poverty, Nova York/Cambridge, Russell Sage Foundation/Harvard University Press.

FIGUEIREDO, A.; TORRES, H.; LIMONGI, F.; ARRETCHE, M. \& BICHIR, R. (2005), Relatório final do projeto "Projeto BRA/04/052 - Rede de Pesquisa e Desenvolvimento de Políticas Públicas: REDE-IPEA II'. Brasília (mimeo).

GOHN, M. (1991), Movimentos sociais e luta pela moradia. São Paulo: Loyola.

GROISMAN, F. \& SUÁREZ, A. (2005), "Urban segregation in the greater Buenos Aires area". Texto apresentado na "Conference on spatial differentiation and governance in the Americas", realizada no Texas, de 17 a 19 de novembro.

GURZA LAVALLE, A \& CASTELLO, G. (2004), "As benesses deste mundo associativismo religioso e inclusão socioeconômica". Novos Estudos Cebrap, 28, mar.

JACOBI, P. (1989), Movimentos sociais e Políticas Públicas: demandas por saneamento básico e saúde: São Paulo 1978-84. São Paulo, Cortez.
JARGOWSKI, P. (1997), Poverty and place: ghettos, barrios and the American city. Nova York: Russell Sage Foundation.

KAZTMAN, R. \& RETAMOSO, A. (2005), "Spatial segregation, employment and poverty in Montevideo". Cepal Review, 85: 125-141 abr.

KOWARICK, L. (1979), A espoliação urbana. Rio de Janeiro, Paz e Terra. . (2001), "Viver em risco: sobre a vulnerabilidade no Brasil urbano". Novos Estudos Cebrap, 63: 9-30.

. (no prelo), "As favelas em São Paulo: sociologia, história e etnologia". São Paulo, 2005.

MARICATO, E. (1996), Metrópole na periferia do capitalismo: ilegalidade, desigualdade e violência. São Paulo, Hucitec.

MARQUES, E. (2000), Estado e redes sociais: permeabilidade e coesão nas politicas urbanas no Rio de Janeiro. Rio de Janeiro, Revan/Fapesp. - (2003), Redes sociais, instituiçôes e atores políticos no governo da cidade de São Paulo. São Paulo, Annablume.

MARQUES, E. \& BICHIR, R. (2001), "Investimentos públicos, infra-estrutura urbana e produção da periferia em São Paulo”. Espaço \& Debates, ano XVII, 42.

MARQUES, E. e TORRES, H. (orgs.). (2005), São Paulo: segregação, pobreza e desigualdade sociais. São Paulo, Senac.

MARQUES, E. \& SARAIVA, C. (2005), "A dinâmica social das favelas da Região Metropolitana de São Paulo", in E. Marques e H. Torres (orgs.), São Paulo: segregação, pobreza e desigualdade sociais. São Paulo, Senac

MASSEY, D. \& DENTON, N. (1993), American apartheid - segregation and the making of the underclass. Harvard, Harvard University Press.

MURRAY, C. (1984), Losing ground. Basic Books.

PRÉTECEILLE, E. (2003), "A evolução da segregação social e das desigualdades urbanas: o caso da metrópole parisiense nas últimas décadas". Caderno CRH, 38, jan-jun.

RECIO, M. E. M. (2003). "Repensando a questão social: trajetórias de algumas interpretações nos Estados Unidos, França e Brasil”. Dissertação de mestrado apresentada ao Depto. de Ciência 
Política da Faculdade de Filosofia, Letras e Ciência Política da FFLCH-USP.

SABATINI, F. (2000), "Reforma de los mercados de suelo en Santiago, Chile: efectos sobre los precios de la tierra y la segregación residencial". Revista Eure, 26, 77, maio. . (2004), "Medición de la segregación residencial: reflexiones metodológicas desde la ciudad latinoamericana", in G. Cáceres e F. Sabatini (eds.). (2004), Barrios cerrados en Santiago de Chile: entre la exclusión y la integración residencial. Lincoln Institute of Land Policy/ PUC-Chile.

SABATINI, F; FLORES, C.; SIERRALTA, C. \& WORMALD, G. (2005), "Residential segregation in Santiago, Chile: 1982-2002 trends and social effects linked to its geographical scale". Texto apresentado na "Conference on Spatial Differentiation and Governance in the Americas", realizada no Texas, de 17 a 19 de novembro.

SADER, E. (1988), Quando novos personagens entram em cena. São Paulo: Paz e Terra.

SANTOS, C. (1979), "Velhas novidades nos modos de urbanização brasileiros", in Lícia do Prado Valladares (org.). (1979), Habitação em questão. Rio de Janeiro: Jorge Zahar.

SANTOS, C. \& BRONSTEIN, O. (1978), "Metaurbanização - o caso do Rio de Janeiro”. Revista de Administração Municipal, ano 25, 149.

SMOLKA, M. O. (1992), "Expulsando os pobres e redistribuindo os ricos - dinâmica imobiliária e (re)estruturação interna na cidade do Rio de Janeiro”. Revista Brasileira de Estudos de População, 9, (1), jan.-jun.

TORRES, H. (2005), "Políticas sociais e território: uma abordagem metropolitana", in E. Marques e H. Torres (orgs.), São Paulo: segregação, pobreza e desigualdade sociais, São Paulo, Senac.

TORRES, H. \& BICHIR, R. (2009), "Residential segregation in São Paulo: consequences for urban policies", in B. R. Roberts e R. H. Wilson (eds.), Urban segregation and governance in the Americas. Nova York, Palgrave Macmillan.

VETTER, D. \& MASSENA, R. (1981), "Quem se apropria dos benefícios líquidos dos investimentos do Estado em infra-estrutura? - Uma teoria da causação circular”, in L. A. Machado da
Silva (org.), Solo urbano - Tópicos sobre o uso da terra, Rio de Janeiro: Jorge Zahar.

VILLAÇA, F. (2000), Espaço intra-urbano no Brasil. São Paulo: Nobel.

WACQUANT, L. (1996), "Três premissas perniciosas no estudo do gueto norte-americano". Mana. Estudos de Antropologia Social, 2 (2): 14561.

(2001), Os condenados da cidade: estudos sobre marginalidade avançada. Rio de Janeiro, Revan/Fase.

WILSON, W. J. (1987), The truly disadvantage: the inner city, the underclass and public policy. Chicago, University of Chicago Press.

WORLD BANK (1999), Entering the 21st Century: world development report 1999/2000. Oxford, Oxford University Press.

YINGER, J. (2001), "Housing discrimination and residential segregation as causes of poverty", in S. Danziger e R. Haveman (eds.), Understanding poverty. Nova York/Cambridge, Russell Sage Foundation/Harvard University Press. 


\section{Anexo}

Mapa 1

Áreas de ponderação da Amostra do Censo classificadas segundo macrorregiões. Município de São Paulo, 2000.

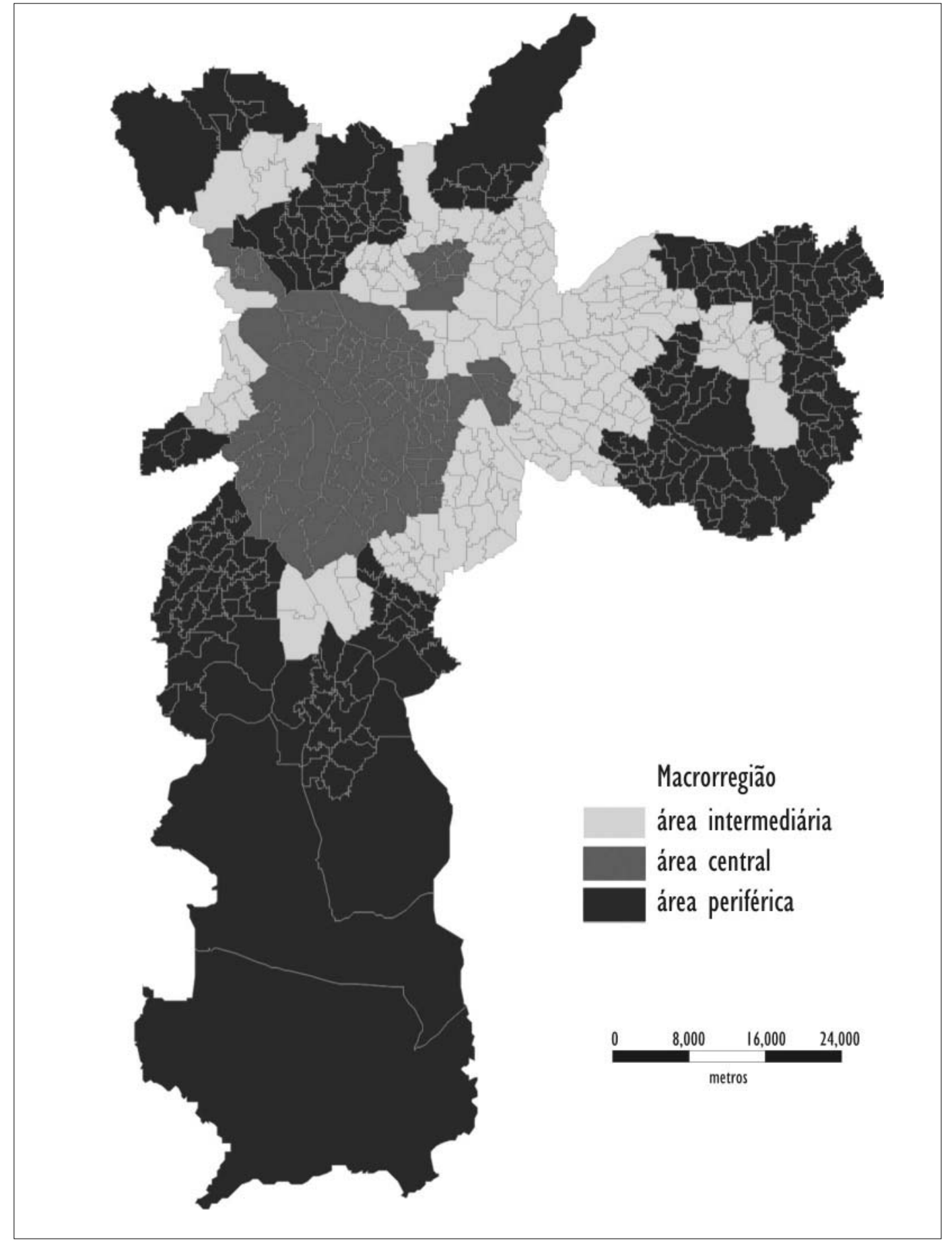

Fonte: Microdados da Amostra do Censo Demográfico 2000, IBGE. 


\section{DETERMINANTES DO ACESSO À INFRA-ESTRUTURA URBANA NO MUNICÍPIO DE SÃO PAULO}

\section{Renata Mirandola Bichir}

Palavras-chave: Segregação; Pobreza; Políticas públicas; Infra-estrutura; São Paulo.

Este trabalho analisa os fatores que condicionam o acesso da população mais pobre do município de São Paulo às políticas de infra-estrutura urbana (serviços de água, luz, esgotamento sanitário, coleta de lixo, entre outros). As análises baseiam-se em um survey, realizado em 2004 , entre os $40 \%$ mais pobres, que analisou condições gerais de vida e de acesso a políticas. A autora explora as diferentes dimensões que interferem no acesso a esses serviços urbanos por meio de um modelo multivariado. Os resultados obtidos revelam elevados níveis de cobertura mesmo entre a população mais pobre e apontam para o impacto da segregação residencial sobre as condições de acesso à infra-estrutura urbana. Indicam também expressiva presença do Estado mesmo nas áreas periféricas, apesar de ainda haver diferenciais de qualidade em relação a outras áreas do município. Desse modo, o artigo procura contribuir para a compreensão das desigualdades de acesso às políticas públicas entre os mais pobres, detalhando a complexidade das situações de déficit de acesso a serviços urbanos em São Paulo.

\section{DETERMINANTS OF URBAN INFRASTRUCTURE ACCESS IN THE CITY OF SÃO PAULO}

\author{
Renata Mirandola Bichir
}

Keywords: Segregation; Poverty; Public policies; Infra-structure; São Paulo.

The article analyses the key determinants of poor people's access to urban infrastructure policies (water, electricity, sewage, garbage collection, among others) in São Paulo. The analysis is based on a survey carried out in 2004 among the poorest $40 \%$ population, which examined poor people living conditions and their access to several public policies. Departing from a brief discussion on the determinants of access to the policies of urban infrastructure, with emphasis on residential segregation, the article explores the different dimensions that interfere with access to urban services using a multivariate model. The results show high levels of coverage even among the poorest people and point to the impact of residential segregation on the conditions of access to urban infrastructure. There is a significant presence of the state even in peripheral areas, although there are still differences in quality compared to other areas of the city. Thus, the article seeks to contribute to the understanding of inequalities in poor people's access to public policies, detailing the heterogeneity of the situations of lack of access to urban services in Sao Paulo.
FACTEURS DÉTERMINANTS DE L'ACCÈS À L'INFRASTRUCTURE URBAINE DANS LA COMMUNE DE SÃO PAULO

\section{Renata Mirandola Bichir}

Mots-clés: Ségrégation; Pauvreté; Politiques publiques; Infrastructure; São Paulo.

Ce travail analyse les facteurs qui conditionnent l'accès de la population la plus pauvre de la commune de São Paulo aux politiques d'infrastructure urbaine (services d'approvisionnement en eau, électricité, assainissement, ramassage des ordures, dentre autres). Les analyses se fondent sur une enquête qui a eu lieu en 2004 , parmi les $40 \%$ les plus pauvres. L'enquête a analysé les conditions générales de vie et d'accès aux politiques publiques de cette population. L'auteur explore les différentes dimensions qui affectent l'accès à ces services urbains par un modèle multivarié. Les résultats obtenus révèlent de hauts niveaux de couverture même parmi la population la plus pauvre, et indiquent l'impact de la ségrégation résidentielle sur les conditions d'accès à l'infrastrucutre urbaine. Ils indiquent également la présence de l'État même dans les régions périphériques, malgré l'existence de différences de qualité par rapport à d'autres régions de la commune. L'article cherche, ainsi, à contribuer à la compréhension des inégalités d'accès à des politiques publiques entre les plus pauvres, tout en détaillant la compléxité des situations de déficit d'accès à des services urbains à São Paulo. 